\title{
PHASE SEPARATION IN POLYMER SOLUTIONS. II. DETERMINATION OF THERMODYNAMIC PARAMETERS OF POLY(2,6-DIMETHYL-1, 4-PHENYLENE OXIDE) TOLUENE MIXTURES
}

\section{P. T. VAN EMMERIK and C. A. SMOLDERS}

Twente University of Technology, Enschede, Netherlands

\section{SYNOPSIS}

In liquid systems where it is possible to perform light scattering experiments at the melting points of polymer solutions without nucleation taking place because of undercooling, the thermodynamic parameters necessary to calculate the correction parameter $g$ in the Flory-Huggins equation as modified by Koningsveld can be determined. In the system poly(2,6-dimethyl 1,4-phenylene oxide)-toluene crystallization will be induced by liquid-liquid phase separation at temperatures below the melting points. The Huggins interaction parameter $x$, calculated from light scattering data, shows negative values for solutions up to 24.5 weight per cent of polymer. This indicates specific interactions between polymer and solvent molecules. A combination of data from light scattering and from calculations based on the theory of melting point depression affords the values necessary for calculating the free enthalpy of mixing $\Delta \mathrm{G}$.

\section{INTRODUCTION}

When homogeneous mixtures of poly(2,6-dimethyl-1,4-phenylene oxide) (PPO) and toluene are cooled a phase transition is initiated by liquid-liquid phase separation [1]. Depending upon temperature and composition two mechanisms will be possible, nucleation and growth [2] or the so-called spinodial decomposition [3]. Spinodial decomposition can be detected experimentally only if the contribution of nucleation and growth to the phase separation during cuoling can be ignored. To this purpose nucleation and growth should be a slow process, which is indeed the case for PPO-toluene [1] and PPO-caprolactam $[4,5]$.

When liquid-liquid phase separation has occurred in these systems, solventinduced crystallization [6] of the PPO gradually takes place in regions rich in polymer. Upon rewarming the mixture will become homogeneous at a lower melting point of the crystalline material. As a result three phase-separation curves in the system PPO-toluene or PPO-caprolactam can be determined: the 
spinodial A (rapid cooling), the cloud point curve B (extremely slow cooling), and the melting point curve $\mathrm{C}$ (warming) (Fig. 1).

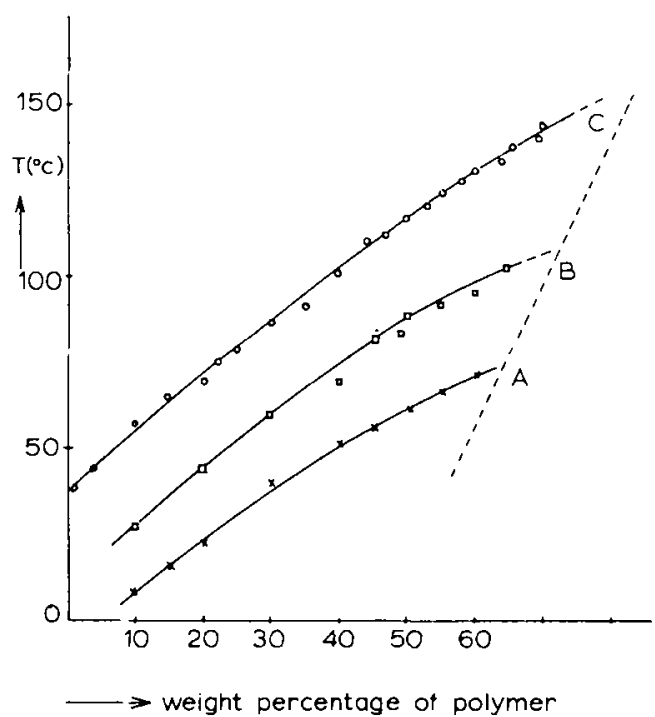

FIG. 1. Phase separation curves of PPO-toluene solutions: A/spinodial; B/cloud point curve; (C) melting point curve.

The separation range of the amorphous phase in PPO-toluene is very broad, showing no maximum up to $70 \%$ by weight of PPO. Thus it seems of interest to compare the thermodynamic parameters of this system with those obtained for systems like polystyrene-cyclohexane [7], where rather narrow amorphousphase separation ranges are found.

\section{OUTLINE OF THIS WORK}

In a recent article, Scholte [8] discussed the possibility of determining thermodynamic parameters of a concentrated polymer-solvent system by light scattering experiments. In this way $\Delta \mu_{0}$ (the chemical potential of the solvent in solution minus the chemical potential of the pure solvent) can be calculated and from $\Delta \mu_{0}$ the Flory-Huggins interaction parameter $\chi$ can be evaluated.

In the original formulations Flory and Huggins supposed $\chi$ to be independent of the weight fraction $w$ of the polymer [9] and of the temperature $T$, but later investigations proved that for many systems this is not quite correct. Koningsveld [10] has modified the Flory-Huggins treatment by introduction of a weight and temperature dependent parameter $g(w, T)$ into the expression for $\Delta G_{m}$, the free enthalpy of mixing. For a quantitative evaluation of this parameter $g(w, T)$ quantitative values of $\Delta \mu$ (the chemical potential of the polymer in solution minus that in the pure liquid state) as a function of $w$ and $T$ are needed, in addition to quantitative values of $\Delta \mu_{0}(w, T)$. Light scattering experiments afford values of $\partial \mu / \partial w$ and $\Delta \mu_{0}$ only. 
However, in the theory of melting point depression, the difference between the melting point of the pure polymer and the polymer in solution is related to the chemical potential of the polymer-solvent system and quantitative values of $\Delta \mu$ at the various melting points can be calculated [11]. When these values are combined with those obtained by light scattering, quantitative values of $\Delta \mu$ over a range of $w$ and $T$ can be determined which enables $g$ to be calculated over the same range of $w$ and $T$. As a result, in all systems where a melting point curve exists, light scattering measurements over a range of concentration and temperatures including points of the melting point curve can afford all parameters necessary to calculate the free enthalpy (Gibbs free energy) of mixing $\Delta \mathrm{G}$ over a range of concentrations and temperatures.

For the system PPO-toluene, light scattering experiments have been performed below and including the melting point curve (curve C, Fig. 1). The measurements are possible in this system, since phase separation is initiated by liquid-liquid phase decomposition (curve B) followed by crystallization in the regions rich in polymer [1].

\section{EXPERIMENTAL}

The light scattering experiments were performed with a Sofica photogoniometer. The intensity of scattered light was measured at different angles in order to allow extrapolation to zero scattering angle.

The temperature was controlled by means of circulating water from a thermostat. The solutions were made dust free by filtration through a commercial Millipore filter.

Refractive index increments were measured with a differential refractometer.

Experiments were carried out with solutions of PPO in toluene at concentrations up to $24.5 \%$ by weight of PPO.

The PPO sample had number-average and weight-average molecular weights of $M_{n}=25,000$ and $M_{w}=49,000$. The toluene was Baker Analyzed Reagent Grade.

\section{THERMODYNAMIC FORMULATIONS}

To calculate the free enthalpy of mixing $\Delta G$, the Flory-Huggins equation expressed in weight fractions [7] is used.

$$
\frac{\Delta \mathrm{G}}{\mathrm{RT}}=\left[\mathrm{w}_{\mathrm{o}} \ln \mathrm{w}_{\mathrm{o}}+\sum_{\mathrm{i}} \frac{\mathrm{M}_{\mathrm{o}}}{\mathrm{M}_{\mathrm{i}}} \mathrm{w}_{\mathrm{i}} \ln \mathrm{w}_{\mathrm{i}}+\mathrm{gw} \mathrm{w}\right]
$$

where $\Delta G$ is the free enthalpy of mixing of $M_{0}$ grams of solution; $w_{0}$ is the weight fraction of the solvent; $w_{i}$ is the weight fraction of polymer component $i$; $\mathrm{w}$ is the total weight fraction of the polymer; $\mathrm{g}$ is an empirical correction factor; 
$M_{0}$ is the molecular weight of the solvent; and $M_{i}$ is the molecular weight of the polymer component $i$. Differentiation of $\Delta G$ with respect to the number of moles of the various components yields expressions for the chemical potentials:

$$
\frac{\Delta \mu_{0}}{\mathrm{RT}}=\ln (1-\mathrm{w})+\left(1-\frac{\mathrm{M}_{\mathrm{o}}}{\mathrm{M}_{\mathrm{n}}}\right) \mathrm{w}+\left[\mathrm{g}-(1-\mathrm{w}) \frac{\partial \mathrm{g}}{\partial \mathrm{w}}\right] \mathrm{w}^{2}
$$

and

$$
\frac{\Delta \mu_{i}}{R T}=\ln w_{i}+1-\frac{M_{i}}{M_{n}} w-\frac{M_{i}}{M_{o}}(1-w)+\left[g+w \frac{\partial g}{\partial w}\right] \frac{M_{i}}{M_{o}}(1-w)^{2}
$$

The factor

$$
\left[g-(1-w) \frac{\partial g}{\partial w}\right]
$$

representing the Huggins interaction parameter $\chi$ can be calculated if $\Delta \mu_{0}$ is known as a function of $\mathrm{w}$ and $\mathrm{T}$.

If $\Delta \mu_{\mathrm{i}}$ is known, then

$$
\left[g+w \frac{\partial g}{\partial w}\right]
$$

can also be calculated. Combination of eqs. (4) and (5) yields values for the interaction parameter $\mathrm{g}$. With these $\mathrm{g}$ values (assumed to be independent of molecular weight) the $\Delta \mathrm{G}$ curve can be calculated with eq. (1).

\section{LIGHT SCATTERING}

From the general theory of light scattering of solutions as applied to polymer solutions $[12,13]$, Scholte [9] derived an equation which relates the scattered light intensity, extrapolated to zero scattering angle, to the chemical potentials of the solution, leading to

$$
-\left(\frac{\partial\left(\Delta \mu_{0}\right)}{\partial w}\right)_{M_{n}}=\operatorname{RTM}_{0}\left[\frac{2 \pi^{2} n_{B}^{2}}{N_{A} \lambda^{4} R_{B}}\left(\frac{d n}{d w}\right)^{2} \frac{w}{\rho(\alpha \Delta I)_{\theta}=0}+\frac{1}{M_{n}}-\frac{1}{M_{w}}\right]
$$

and 


$$
\left(\frac{\partial \mu}{\partial w}\right)_{M W D}=\operatorname{RTM}_{n}\left[\frac{2 \pi^{2} n_{B}^{2}}{N_{A} \lambda^{4} R_{B}}\left(\frac{d n}{d w}\right)^{2} \frac{1-w}{\rho(\alpha \Delta I)_{\theta=0}}+\frac{1-w}{w}\left(\frac{1}{M_{n}}-\frac{1}{M_{w}}\right)\right]
$$

Here, $\Delta \mathrm{I}$ is the intensity of light scattered from the solution minus that from the pure solvent, relative to the light intensity due to benzene, and measured perpendicular to the incident beam. Further, $\alpha$ denotes an angle factor; $(\alpha \Delta \mathrm{I})_{\theta=0}$ is the intensity of scattered light extrapolated to zero angle $\theta ; n_{B}$ is the refractive index of benzene; $N_{A}$ is Avogadro's number; $\lambda$ is wavelength in vacuo; $R_{B}$ is Rayleigh's ratio factor of benzene; $\rho$ is the density of the solution; $\mathrm{dn} / \mathrm{dw}$ is the refractive index increment; $M_{w}$ is the weight-average molecular weight of the polymer; and MWD indicates the molecular weight distribution.

The righthand side of eqs. (6) and (7) can be determined experimentally and yields $\left(\partial\left(\Delta \mu_{0}\right) / \partial_{\mathrm{w}}\right)_{\mathrm{M}_{\mathrm{n}}}$ and $(\partial \mu / \partial \mathrm{w})_{\mathrm{MWD}}$, respectively, at the concentration used. When this has been done for a number of concentrations, subsequent graphical integration of $\left(\partial \Delta \mu_{0} / \partial w\right)_{M_{n}}$ from zero to the appropriate value of $w$, gives the dependence of $\Delta \mu_{0}$ on $w$ at constant temperature (integration constant zero since $\Delta \mu_{0}=0$ at $\mathrm{w}=0$ ). With the values of $\Delta \mu_{0}, \chi$ can now be calculated by use of eq. (2). Integration of $(\partial \mu / \partial w)_{M W D}$ would give values for $\Delta \mu$ for all desired values of $w$ if the integration constants were known. In this case, however, since $\Delta \mu \neq 0$ at $w=0$, the integration constant must be obtained independently from other data.

\section{MELTING POINT DEPRESSION}

The theory of the melting point depression [9] offers a method to calculate values of $\Delta u$ for polymer-solvent solutions at the melting point of the crystalline material. The condition of equilibrium between crystalline polymer and the polymer in solution yields

$$
\mu_{\mathrm{u}}^{\mathrm{c}}-\mu_{\mathrm{u}}^{\mathrm{o}}=\mu_{\mathrm{u}}^{1}-\mu_{\mathrm{u}}^{\mathrm{o}}
$$

where $\mu_{\mathrm{u}}^{\mathrm{c}}$ is the chemical potential per repeat unit in crystalline polymer; $\mu_{\mathrm{u}}^{\mathrm{o}}$ is the same for the liquid polymer; and $\mu_{u}^{1}$ is the same for polymer in solution. This equation can be written as

$$
-\Delta \mu_{\mathrm{f}, \mathrm{u}}=+\Delta \mu_{\mathrm{m}, \mathrm{u}}
$$

where $f$ indicates fusion, $m$ indicates mixing.

Hoffman [14] has shown that to a good approximation $\Delta \mu_{\mathrm{f}, \mathrm{u}}$ may be written as

$$
\Delta \mu_{\mathrm{f}, \mathrm{u}}=\Delta \mathrm{H}_{\mathrm{u}}^{\mathrm{o}}\left(\Delta \mathrm{T} \cdot \mathrm{T}_{\mathrm{m}} / \mathrm{T}_{\mathrm{m}}^{\mathrm{o}}{ }^{2}\right)
$$


in which $\Delta \mathrm{H}_{u}{ }^{\circ}$ is the molar enthalpy of fusion per repeat unit of pure polymer; $T_{m}$ is the melting point of the solution; $T_{m}{ }^{\circ}$ is the melting point of the pure polymer; and $\Delta \mathrm{T}=\mathrm{T}_{\mathrm{m}}{ }^{\circ}-\mathrm{T}_{\mathrm{m}}$.

Combination of eqs. (9) and (10) yields [11]:

$$
\Delta \mu_{\mathrm{m}, \mathrm{u}}=-\Delta \mathrm{H}_{\mathrm{u}}^{\mathrm{o}} \Delta \mathrm{T} \cdot \mathrm{T}_{\mathrm{m}} /\left(\mathrm{T}_{\mathrm{m}}^{\mathrm{o}}\right)^{2}
$$

and for one mole of polymer solution:

$$
\Delta \mathrm{T}=-\Delta \mu_{\mathrm{m}} \quad\left(\mathrm{T}_{\mathrm{m}}^{\mathrm{o}}\right)^{2} / \Delta \mathrm{H}^{\mathrm{o}} \cdot \mathrm{T}_{\mathrm{m}}
$$

\section{TABLE I}

\begin{tabular}{|c|c|c|c|c|c|}
\hline $\mathbf{w}$ & $\mathrm{T}^{\circ} \mathrm{C}$ & $-\Delta \mu_{0} \times 10^{-6} \mathrm{erg} / \mathrm{mole}$ & $x$ & $\rho$ & $\mathrm{dn} / \mathrm{dw}$ \\
\hline 0.009 & $\begin{array}{l}24.5 \\
34.5 \\
45 \\
55 \\
65\end{array}$ & $\begin{array}{l}29.56 \\
31.60 \\
33.11 \\
36.07 \\
37.74\end{array}$ & $\begin{array}{l}-13.53 \\
-14.38 \\
-14.57 \\
-15.45 \\
-15.70\end{array}$ & $\begin{array}{l}0.8675 \\
0.8602 \\
0.8510 \\
0.8400 \\
0.8299\end{array}$ & $\begin{array}{l}0.1075 \\
0.1100 \\
0.1130 \\
0.1140 \\
0.1155\end{array}$ \\
\hline 0.024 & $\begin{array}{l}24.5 \\
34.5 \\
45 \\
55 \\
65\end{array}$ & $\begin{array}{l}79.61 \\
84.10 \\
90.40 \\
93.27 \\
98.03\end{array}$ & $\begin{array}{l}-4.94 \\
-5.06 \\
-5.28 \\
-5.29 \\
-5.41\end{array}$ & $\begin{array}{l}0.8707 \\
0.8614 \\
0.8522 \\
0.8429 \\
0.8340\end{array}$ & $\begin{array}{l}0.1075 \\
0.1100 \\
0.1130 \\
0.1140 \\
0.1155\end{array}$ \\
\hline 0.048 & $\begin{array}{l}24.5 \\
34.5 \\
45 \\
55 \\
65\end{array}$ & $\begin{array}{l}166.1 \\
175.2 \\
190.0 \\
191.4 \\
200.7\end{array}$ & $\begin{array}{l}-2.32 \\
-2.39 \\
-2.53 \\
-2.47 \\
-2.51\end{array}$ & $\begin{array}{l}0.8854 \\
0.8765 \\
0.8676 \\
0.8500 \\
0.8401\end{array}$ & $\begin{array}{l}0.1075 \\
0.1100 \\
0.1130 \\
0.1140 \\
0.1155\end{array}$ \\
\hline 0.103 & $\begin{array}{l}24.5^{\mathrm{a}} \\
34.5 \\
45 \\
55 \\
65\end{array}$ & $\begin{array}{l}394.7 \\
409.0 \\
458.5 \\
456.4 \\
465.6\end{array}$ & $\begin{array}{l}-0.93 \\
-0.94 \\
-1.06 \\
-1.01 \\
-0.99\end{array}$ & $\begin{array}{l}0.8900 \\
0.8775 \\
0.8677 \\
0.8580 \\
0.8460\end{array}$ & $\begin{array}{l}0.1075 \\
0.1100 \\
0.1130 \\
0.1140 \\
0.1155\end{array}$ \\
\hline 0.153 & $\begin{array}{l}24.5^{\mathrm{a}} \\
34.5^{\mathrm{a}} \\
45 \\
55 \\
65\end{array}$ & $\begin{array}{l}600.0 \\
651.9 \\
743.6 \\
742.7 \\
766.2\end{array}$ & $\begin{array}{l}-0.45 \\
-0.50 \\
-0.61 \\
-0.58 \\
-0.58\end{array}$ & $\begin{array}{l}0.9055 \\
0.8870 \\
0.8760 \\
0.8651 \\
0.8550\end{array}$ & $\begin{array}{l}0.1075 \\
0.1100 \\
0.1130 \\
0.1140 \\
0.1155\end{array}$ \\
\hline 0.204 & $\begin{array}{l}45^{a} \\
55 \\
65\end{array}$ & $\begin{array}{l}1074.9 \\
1110.6 \\
1184.3\end{array}$ & $\begin{array}{r}-0.38 \\
-0.38 \\
-0.42\end{array}$ & $\begin{array}{l}0.8850 \\
0.8742 \\
0.8640\end{array}$ & $\begin{array}{l}0.1130 \\
0.1140 \\
0.1155\end{array}$ \\
\hline 0.245 & $\begin{array}{l}45^{a} \\
55 \\
65\end{array}$ & $\begin{array}{l}1308.7 \\
1474.4 \\
1622.7\end{array}$ & $\begin{array}{r}-0.21 \\
-0.29 \\
-0.35\end{array}$ & $\begin{array}{l}0.8944 \\
0.8850 \\
0.8710\end{array}$ & $\begin{array}{l}0.1130 \\
0.1140 \\
0.1155\end{array}$ \\
\hline
\end{tabular}

Chemical Potentials and Interaction Parameters of PPO-Toluene Solutions

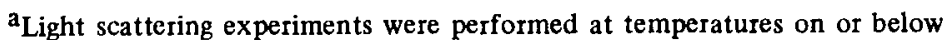
the cloud point curve. 
Since $\Delta \mathrm{T}, \mathrm{T}_{\mathrm{m}}{ }^{\mathrm{o}}, \mathrm{T}_{\mathrm{m}}$ and $\Delta \mathrm{H}^{\mathrm{o}}$ can be determined experimentally, $\Delta \mu_{\mathrm{m}}$ can be calculated for each solution at its melting point. Combination of $\Delta \mu_{\mathrm{m}}$ values so obtained with light scattering data for $\partial \mu / \partial w$ over a range of concentrations and at constant temperature enables the integration constant at that temperature to be calculated. A numerical example follows in the next section.

In this way quantitative values for both $\Delta \mu_{0}$ and $\Delta \mu$ could be obtained in the concentration range from 0 to $24.5 \%$ of polymer and for temperatures between $25^{\circ} \mathrm{C}$ and $65^{\circ} \mathrm{C}$.

With eqs. (2) and (3) the interaction parameter $g$ could be obtained in the same concentration temperature ranges.

\section{RESULTS}

Crystallization of PPO from solution is induced only after liquid-liquid phase separation has occurred. The latter takes place at lower temperatures than melting of the polymer crystals. Therefore it is experimentally possible to obtain light scattering data corresponding to concentrations and temperatures on the melting point curve. In fact most light scattering data, because of limits set by the necessity of working below about $65^{\circ} \mathrm{C}$, originate from the region between the melting point curve and the cloud point curve (curve $\mathrm{C}$ and curve $\mathrm{B}$, respectively, in Fig. 1). Even measurements below the cloud point curve were possible here owing to an induction period for nucleation.

Light scattering data have been obtained at temperatures of $24.5,34.5,45$, 55 , and $65^{\circ} \mathrm{C}$ for solutions of PPO in toluene at concentrations from $\mathrm{w}=0.009$ up to $\mathrm{w}=0.245$.

By use of eqs. (6) and (7), values for $\left(\partial \Delta \mu_{0} / \partial w\right) M_{n}$ and $(\partial \mu / \partial w)_{M w D}$ were calculated with $n_{B}$ taken to be $1.502, \lambda=546 \mathrm{~m} \mu$, and $R_{B}=16.3 \times 10^{-6} \mathrm{~cm}^{-1}$. The resulting values for $\rho$ and $\mathrm{dn} / \mathrm{dw}$ are compiled in Table $\mathrm{I}$, which also contains values of $\Delta \mu_{0}$ for various concentrations and temperatures, obtained by graphical integration of $\left(\partial \Delta \mu_{0} / \partial w\right)_{M_{n}}$ versus $w$. We note the negative $\chi$ values calculated via eq. (2). Figure 2 shows $(\partial \mu / \partial w)_{M W D}$ as a function of $w$ at different temperatures. Because of the details of the curves at higher concentrations the points at $w=0.009$ have not been included.

Table II contains the data used to calculate $\Delta \mu$. Values for $\Delta \mu_{\mathrm{mp}}$ were calculated from the melting point curve via eq. (12), with $\mathrm{T}_{\mathrm{m}}{ }^{0}=513 \mathrm{~K}$ (measured by differential scanning calorimetry and $\Delta \mathrm{H}^{0}=120 \mathrm{kcal} / \mathrm{mole}$ [15].

The $\Delta \mu_{1 s}^{\prime}$ values were obtained by integration of $(\partial \Delta \mu / \partial w)_{M W D}$ from light scattering data given in Figure 2. As an example how the integration constants were obtained we consider the data for a PPO solution with $w=0.153$. At the melting point $T_{m}=65^{\circ} \mathrm{C}$ (Fig. 1) the value of $\Delta \mu_{\mathrm{mp}}=-113.3 \times 10^{10} \mathrm{erg} / \mathrm{mole}$. From light scattering data at $\mathrm{T}=65^{\circ} \mathrm{C}$ we obtain, by graphical integration from $\mathrm{w}=0$ to $\mathrm{w}=0.153, \Delta \mu_{\mathrm{ls}}^{\prime}=454.0 \times 10^{10} \mathrm{erg} / \mathrm{mole}$. The integration constant to be used for all other $(\partial \mu / \partial w)_{M W D}$ data at that temperature is the difference between these two values and yields 


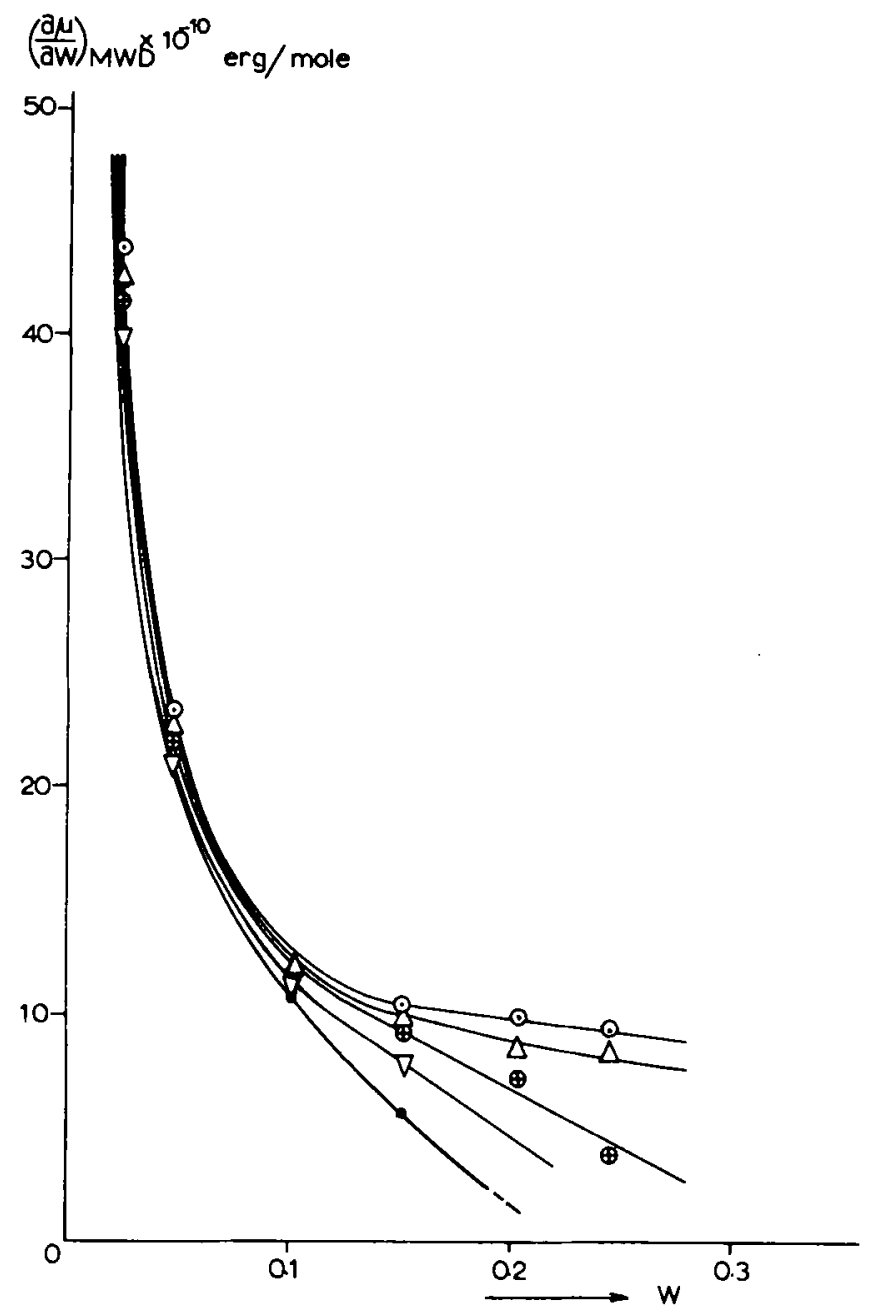

FIG. 2. $(\partial \mu / \partial \mathrm{w})_{\mathrm{MWD}}$ for PPO-toluene solutions determined at different temperatures. (•) $\mathrm{T}=24.5^{\circ} \mathrm{C} ;(\nabla) \mathrm{T}=34.5^{\circ} \mathrm{C} ;(\oplus) \mathrm{T}=45^{\circ} \mathrm{C} ;(\Delta) \mathrm{T}=55^{\circ} \mathrm{C} ;(0) \mathrm{T}=65^{\circ} \mathrm{C}$.

$$
\mathrm{C}=(-113.3-454.0) \times 10^{10} \mathrm{erg} / \mathrm{mole}=-567.7 \times 10^{10} \mathrm{erg} / \mathrm{mole}
$$

When the data for $\Delta \mu_{0}$ and $\Delta \mu$ from Tables I and II are inserted into eqs. (2) and (3), the $g$ values as given in Table II and Figure 3 are obtained. The $g$ values tabulated have been used to calculate the $\Delta \mathrm{G} / \mathrm{RT}$ for $\mathrm{M}_{0}$ grams of solution for each $w$ and $T$ considered. Results are shown in Figures 4 and 5 and in Table III. Data for $w=0.009$ at different temperatures have not been used in the calculation of $\mathrm{g}$ because the melting point was below $\mathrm{T}=24.5^{\circ} \mathrm{C}$ at this concentration. 
TABLE II

Chemical Potentials and Interaction Parameters g of PPO-Toluene Solutions

\begin{tabular}{|c|c|c|c|c|c|c|c|}
\hline w & 0.009 & 0.024 & 0.048 & 0.103 & 0.153 & 0.204 & 0.245 \\
\hline \multicolumn{8}{|l|}{$\mathrm{T}=34.5^{\circ} \mathrm{C}$} \\
\hline$\mu_{l \mathrm{~s}}^{\prime} \cdot 10^{-10 \mathrm{a}}$ & 116.7 & 224.7 & 288.0 & 370.8 & 417.7 & & \\
\hline$\Delta \mu_{\mathrm{mp}} \cdot 10^{-10}$ & -120.9 & & & & & & \\
\hline integr. $c \cdot 10^{-10}$ & -237.6 & & & & & & \\
\hline$\Delta \mu \cdot 10^{-10}$ & -120.9 & -13.1 & +50.4 & +133.2 & +180.1 & & \\
\hline g & 0.709 & 0.870 & 0.970 & 1.122 & 1.235 & & \\
\hline \multicolumn{8}{|l|}{$\mathrm{T}=45^{\circ} \mathrm{C}$} \\
\hline$\mu_{l \mathrm{~s}}^{\prime} \cdot 10^{-10 \mathrm{a}}$ & 119.0 & 228.9 & 294.2 & 382.8 & 432.6 & 470.2 & 490.2 \\
\hline$\Delta \mu_{\mathrm{mp}} \cdot 10^{-10}$ & & & -118.8 & & & & \\
\hline integr. $\mathrm{c} \cdot 10^{-10}$ & & & -413.0 & & & & \\
\hline$\Delta \mu \cdot 10^{-10}$ & -294.0 & -184.1 & -118.8 & -30.2 & +19.6 & +57.2 & +77.2 \\
\hline $\mathrm{g}$ & 0.441 & 0.621 & 0.712 & 0.850 & 0.943 & 1.026 & 1.094 \\
\hline \multicolumn{8}{|l|}{$\mathrm{T}=55^{\circ} \mathrm{C}$} \\
\hline$\mu_{l s}^{\prime} \cdot 10^{-10 a}$ & & 234.6 & 298.2 & 402.2 & 440.0 & 476.4 & 500.0 \\
\hline$\Delta \mu_{\mathrm{mp}} \cdot 10^{-10}$ & & & & -116.2 & & & \\
\hline integr. $c \cdot 10^{-10}$ & & & & -518.4 & & & \\
\hline$\Delta \mu \cdot 10^{-10}$ & & -283.8 & -220.2 & -116.2 & -78.4 & -42.0 & -18.4 \\
\hline g & & 0.488 & 0.576 & 0.727 & 0.790 & 0.855 & 0.899 \\
\hline \multicolumn{8}{|l|}{$\mathrm{T}=65^{\circ} \mathrm{C}$} \\
\hline$\mu_{l \mathrm{~s}}^{\prime} \cdot 10^{-10 \mathrm{a}}$ & & 235.8 & 307.2 & 404.8 & 454.0 & 505.6 & 540.1 \\
\hline$\Delta \mu_{\mathrm{mp}} \cdot 10^{-10}$ & & & & & -113.3 & & \\
\hline integr. $c \cdot 10^{-10}$ & & & & & -567.3 & & \\
\hline$\Delta \mu \cdot 10^{-10}$ & & -331.5 & -260.1 & -162.5 & -113.3 & -61.7 & -27.2 \\
\hline $\mathrm{g}$ & & 0.436 & 0.530 & 0.670 & 0.741 & 0.820 & 0.870 \\
\hline
\end{tabular}

${ }^{\mathrm{a}}$ Unit: erg/mole.

TABLE III

Values of $\Delta G / R T \times 10^{5}$ for Solutions of PPO in Toluene

\begin{tabular}{llrrrrrr}
\hline & & & \multicolumn{7}{c}{$\mathrm{w}$} \\
$\mathrm{T}^{\circ} \mathrm{C}$ & 0.009 & 0.024 & 0.048 & 0.103 & 0.153 & 0.204 & 0.245 \\
\hline 34.5 & -279 & -366 & -305 & 530 & 1835 & & \\
45 & -518 & -950 & -1484 & -1983 & -1949 & -1621 & -1110 \\
55 & & -1261 & -2105 & -3120 & -3931 & -4397 & -4716 \\
65 & & -1383 & -2315 & -3646 & -4579 & -4965 & -5254 \\
\hline
\end{tabular}




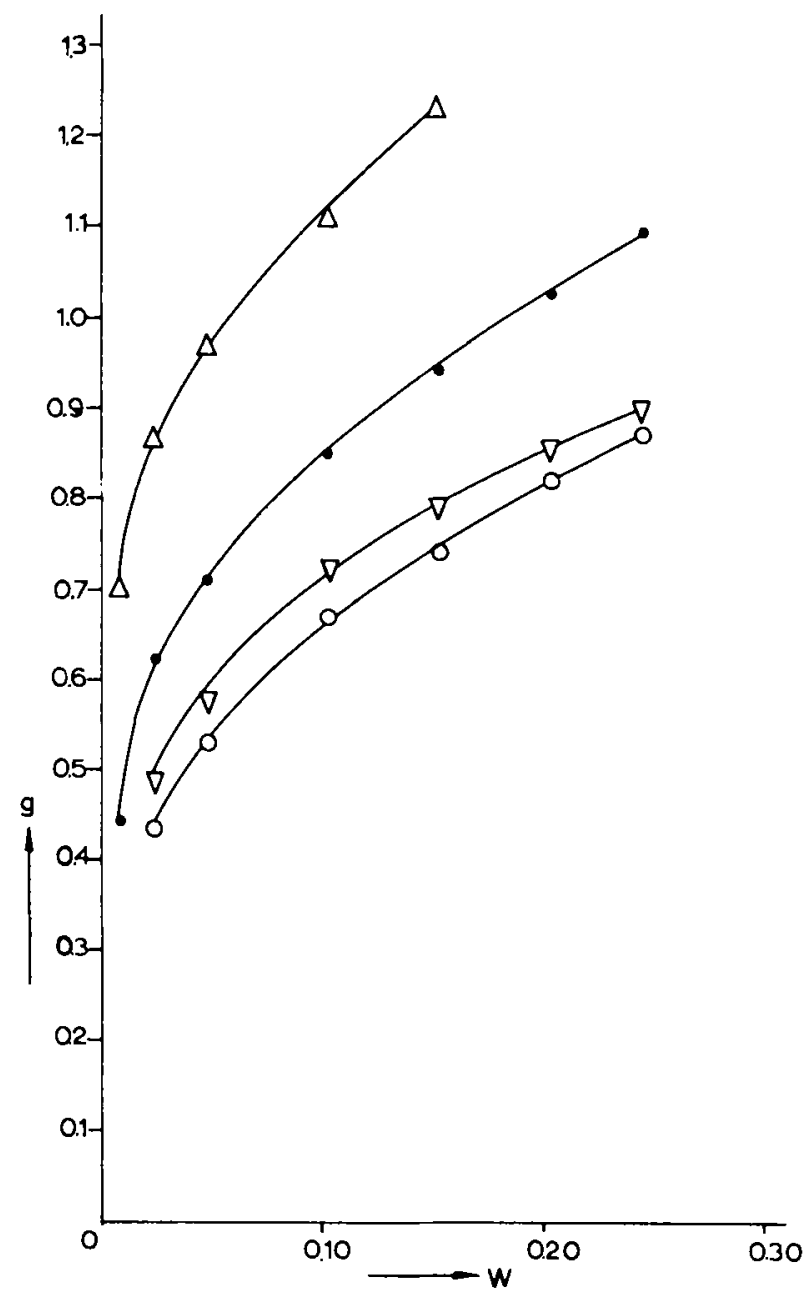

FIG. 3. Plots of $\mathrm{g}$ vs. concentration of PPO-toluene solutions. $(\Delta) \mathrm{T}=34.5^{\circ} \mathrm{C} ;(\bullet) \mathrm{T}=45^{\circ} \mathrm{C}$; $(\nabla) \mathrm{T}=55^{\circ} \mathrm{C} ;(\circ) \mathrm{T}=65^{\circ} \mathrm{C}$.

\section{DISCUSSION}

Liquid-liquid phase separation by nucleation and growth at the appropriate temperatures between the cloud point curve $B$ and the spinodial A of Figure 1 will occur after induction times which are very short at temperatures near curve $A$ but amount to a few hours at temperatures near curve $B$ [16] . For this reason it has been possible to perform light scattering experiments at temperatures not too far below the cloud point curve. As can be seen from Figure 3, the $(\partial \mu / \partial w)_{M W D}$ values are high at first and constantly decrease. For temperatures which are far enough above the cloud point the values of $(\partial \mu / \partial w)_{M W D}$ at any concentration are simply proportional to the temperature. 


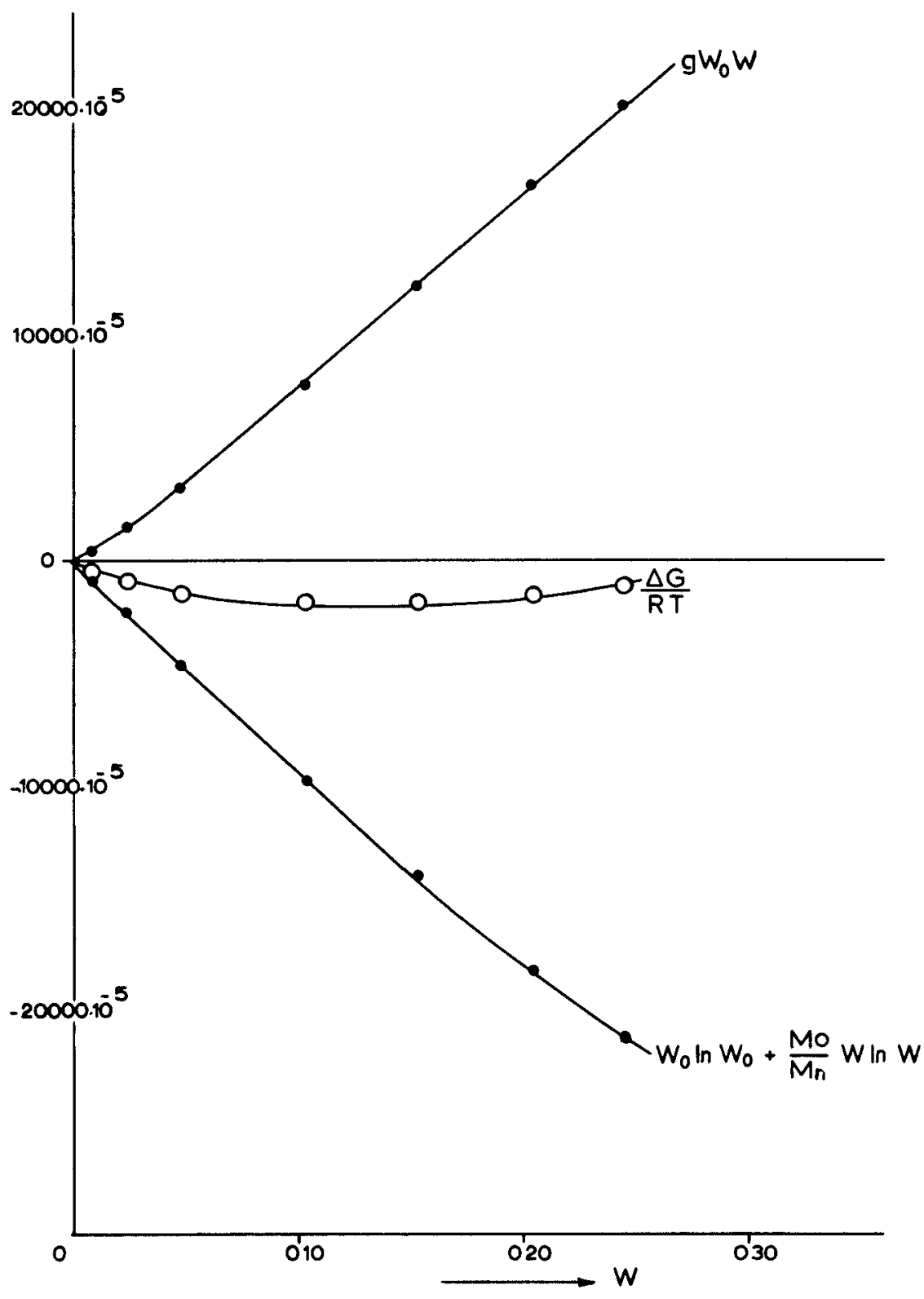

FIG. 4. Calculated $\triangle \mathrm{G} / \mathrm{RT}$ for different PPO-toluene solutions at $\mathrm{T}=45^{\circ} \mathrm{C}$. 


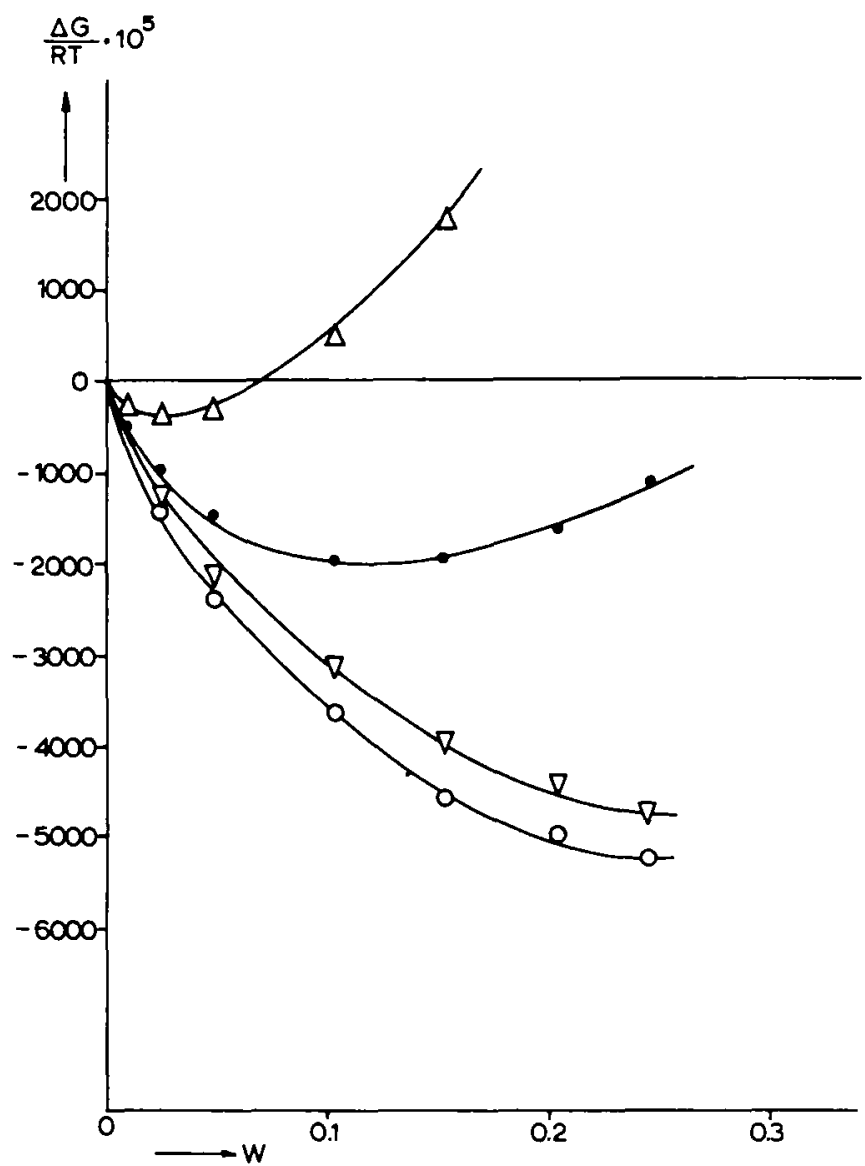

FIG. 5. Plots of $\triangle G / R T$ vs. concentration for PPO-toluene solutions at different temperatures. $(\Delta) \mathrm{T}=34.5^{\circ} \mathrm{C} ;(\bullet) \mathrm{T}=45^{\circ} \mathrm{C} ;(\nabla) \mathrm{T}=55^{\circ} \mathrm{C} ;(\circ) \mathrm{T}=65^{\circ} \mathrm{C}$.

At temperatures near the cloud point (in this case for values of w larger than 0.1 at the experimental temperatures mentioned above) the change of $(\partial \mu / \partial w)_{\text {MWD }}$ is more than proportional to $T$, which means that extra scattering in the neighborhood of the instability region becomes very important.

The spinodial is characterized by $(\partial \mu / \partial w)=0$. The experimentally determined values of $(\partial \mu / \partial w)_{M W D}$ are decreasing functions of $w$ at all temperatures studied, declining to values close to zero. Near the spinodial, light scattering experiments were not possible. Because of liquid-liquid phase separation the scattering intensity increases enormously and the spinodial can not be determined.

When the curves in Figure 2 are assumed to be straight lines for higher concentrations, linear extrapolation of $(\partial \mu / \partial w)_{\text {MWD }}$ to zero yields as the spinodial composition for $\mathrm{T}=24.5,34.5$, and $45^{\circ} \mathrm{C}$, respectively, $\mathrm{w}=0.22, \mathrm{w}=$ 0.27 , and $w=0.33$, in reasonable agreement with the values that can be read from Figure 1 for the experimental spinodial curve. 
The calculated $\chi$ values (Table I) show that $\chi$ is strongly concentration dependent, but is not very sensitive to temperature. In contrast to values for most other polymer-solvent systems, $\chi$ is negative in this case, which means that in

$$
\chi=g-(1-w) \frac{\partial g}{\partial w}
$$

$\partial g / \partial w$ is the dominant factor. Previously, negative $\chi$ values have been found in the system PPO-1-chloronaphthalene [17] and several other polar systems [18]. In these systems there are specific polymer diluent interactions which have not yet been evaluated quantitatively.

The calculated $\mathrm{g}$ values shown in Figure 3 indicate that $\mathrm{g}$ is strongly dependent on $\mathrm{w}$ and $\mathrm{T}$. If liquid-liquid phase separation is to take place the $\Delta \mathrm{G}$ vs. w curve must show a relative and an absolute minimum (or an inflection point and an absolute minimum).

In Figure 5 the $\Delta \mathrm{G}$ curves for $\mathrm{w}$ up to $\mathrm{w}=0.245$ are shown, $\Delta \mathrm{G}$ being expressed in units of RT. Two factors contribute to the $\Delta \mathrm{G}$ curve: $\mathrm{w}_{0} \ln _{0}+$ $\left(\mathrm{M}_{0} / \mathrm{M}_{\mathrm{n}}\right)$ wlnw which is negative for every $\mathrm{w}$, and $\mathrm{gw}_{0} \mathrm{w}$ which is positive. (In fact the number average $\Delta G$ has been calculated.) As can be seen, $g$ values increase with decreasing temperature which means that the solubility of the polymer in the solvent becomes worse at lower temperatures, eventually giving rise to phase separation. For $\mathrm{T}=34.5^{\circ} \mathrm{C}$ and $45^{\circ} \mathrm{C}, \Delta \mathrm{G} / \mathrm{RT}$ versus $\mathrm{w}$ shows a minimum but lack of information about the further course of the $\Delta \mathrm{G}$ curve makes it impossible to draw conclusions about the coexistence lines.

From Figure 1 it is known that at $\mathrm{T}=35^{\circ} \mathrm{C}$ and at $\mathrm{T}=45^{\circ} \mathrm{C}$, respectively, solutions with $w$ larger than $w=0.15$ and $w=0.20$ are not stable and will separate into other phases. The $\Delta \mathrm{G}$ curve for these two temperatures is not at variance with these experimental facts. For $\mathrm{T}=55^{\circ} \mathrm{C}$ and $\mathrm{T}=65^{\circ} \mathrm{C}$ the $\Delta \mathrm{G}$ curve does not show a minimum. Solutions up to $w=0.27$ for $\mathrm{T}=55^{\circ} \mathrm{C}$ and $\mathrm{w}=0.33$ for $\mathrm{T}=65^{\circ} \mathrm{C}$ are homogeneous and will not separate into other liquid phases, which is in accordance with the $\Delta \mathrm{G}$ curve for these two temperatures.

\section{REFERENCES}

[1] P. T. van Emmerik and C. A. Smolders, J. Polym. Sci, C38, 73 (1972).

[2] M. Volmer and A. Weber, Z. Phys. Chem., 119, 277 (1925).

[3] J. W. Cahn, Acta Met., 9, 795 (1961); J. Chem. Phys., 42, 93 (1965).

14] J. J. van Aartsen and C. A. Smolders, Europ. Polym. J., 6, 1105 (1970).

[5] C. A. Smolders, J. J, van Aartsen, and A. Steenbergen, Kolloid-Z. Z. Polym., 243, 14 (1971).

[6] E. P. Magré and J. Boon, IUPAC Intern. Symp., Leiden, 835, 1970.

[7] T. G. Scholte, J. Polym. Sci., A2, 8, 841 (1970).

[8] T. G. Scholte, Europ. Polym. J., 6, 1063 (1970).

[9] P. J. Flory, Principles of Polymer Chemistry, Cornell University Press, Ithaca, N. Y., 1953.

[10] R. Koningsveld, Advan. Koll. Interface Sci., 2, 151 (1968).

[11] J. B. Helms, Dissertation, Groningen, 1970. 
[12] H. C. Brinkman and J. J. Hermans, J. Chem. Phys. 17, 574 (1949).

[13] P. Debye, J. Chem. Phys., 31, 680 (1959).

[14] J. D. Hoffman, J. Chem. Phys, 28, 1192 (1958).

[15] A. R. Schultz and C. R. McCullough, J. Polym. Sci., A2, 7, 1577 (1969).

[16] P. T. van Emmerik and C. A. Smolders, to be published.

[17] F. E. Karasz and O. Mangaraj, Polym. Prepr., Amer. Chem. Soc. Div. Polym. Chem., 12, (1971).

[18] R. Wessling, J. Appl. Polym. Sci., 14, 2263 (1970). 